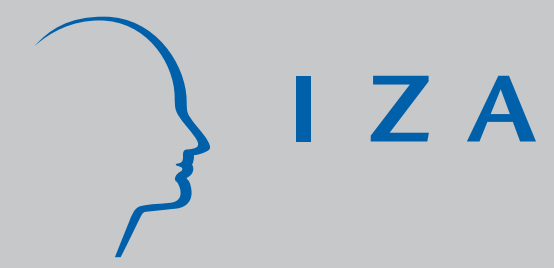

IZA DP No. 357

How Rigid are Nominal Wages?

Evidence and Implications for Germany

Christoph Knoppik

Thomas Beissinger

September 2001 


\title{
How Rigid are Nominal Wages? Evidence and Implications for Germany
}

\author{
Christoph Knoppik \\ University of Regensburg
}

\author{
Thomas Beissinger \\ University of Regensburg and IZA, Bonn
}

Discussion Paper No. 357
September 2001

\author{
IZA \\ P.O. Box 7240 \\ D-53072 Bonn \\ Germany \\ Tel.: +49-228-3894-0 \\ Fax: +49-228-3894-210 \\ Email: iza@iza.org
}

This Discussion Paper is issued within the framework of IZA's research area Mobility and Flexibility of Labor Markets. Any opinions expressed here are those of the author(s) and not those of the institute. Research disseminated by IZA may include views on policy, but the institute itself takes no institutional policy positions.

The Institute for the Study of Labor (IZA) in Bonn is a local and virtual international research center and a place of communication between science, politics and business. IZA is an independent, nonprofit limited liability company (Gesellschaft mit beschränkter Haftung) supported by the Deutsche Post AG. The center is associated with the University of Bonn and offers a stimulating research environment through its research networks, research support, and visitors and doctoral programs. IZA engages in (i) original and internationally competitive research in all fields of labor economics, (ii) development of policy concepts, and (iii) dissemination of research results and concepts to the interested public. The current research program deals with (1) mobility and flexibility of labor markets, (2) internationalization of labor markets and European integration, (3) the welfare state and labor markets, (4) labor markets in transition, (5) the future of work, (6) project evaluation and (7) general labor economics.

IZA Discussion Papers often represent preliminary work and are circulated to encourage discussion. Citation of such a paper should account for its provisional character. 
IZA Discussion Paper No. 357

September 2001

\section{ABSTRACT \\ How Rigid are Nominal Wages? Evidence and Implications for Germany *}

Many of the recent attempts to find evidence of downward nominal wage rigidity in micro data have suffered from a number of problems, including composition bias and the effects of measurement error. In order to avoid these problems we explicitly model the determinants of wage changes and the measurement process that leads to observable earnings changes, thereby directly tackling the question of whether and to which extent downward nominal wage rigidity exists in German micro data. We find a high degree of downward nominal wage rigidity, which for rates of inflation lower than three percent is shown to lead to higher equilibrium unemployment via the generated real wage wedge.

JEL Classification: E24, J30

Keywords: Downward nominal wage rigidity; inflation target; unemployment; Germany

Christoph Knoppik

University of Regensburg

Universitätsstraße 31

93053 Regensburg

Germany

Tel.: +49 9419432700

Email: christoph.knoppik@wiwi.uni-regensburg.de

\footnotetext{
* We would like to thank Walter Oberhofer, Harald Haupt, Joachim Möller, and Johannes Ludsteck for numerous fruitful discussions.
} 


\section{Introduction}

In contrast to the seventies and eighties when double digit inflation rates were rather the rule than the exception, most countries can now look back upon a decade in which central banks have been remarkably successful in taming inflation. In line with these developments, the focus of the academic discussion has shifted to the question of whether monetary authorities should aim at (low) positive instead of zero or even negative inflation rates. This discussion experienced new impetus from the now classic paper of Akerlof, Dickens and Perry (1996), who provided a theoretical basis for the argument in Tobin (1972) that inflation may grease the wheels of the labor market in the presence of downward nominal wage rigidity. Since it is difficult to reconcile the hypothesis of downwardly rigid nominal wages with the postulate of rational behavior, it is all the more important to know whether the validity of the hypothesis can be confirmed empirically. ${ }^{1}$

In this paper we analyze the evidence and policy implications of downward nominal wage rigidity in Germany by using the IAB-Beschäftigtenstichprobe (IABS), which represents the largest and most reliable data source of German income data. One of the reasons why an analysis of the German situation might be of broader interest is due to the fact that the sample includes years with very low or even negative inflation rates. Hence, our analysis is less prone to the critique that behavior with respect to nominal rigidity will be different from that in the sample under close to zero rates of inflation. Furthermore, evidence concerning the extent of downward nominal wage rigidity in Germany will also be of some interest for an evaluation of the inflation policy of the European Central Bank, since Germany is the largest economy in the Euro area.

The most commonly applied approaches for the analysis of downward nominal wage rigidity in micro data make use of the following consideration: If downward nominal wage rigidity does exist, at least some of the desired wage cuts can not be enacted, thus leading to a deformed wage change distribution. Since inflation shifts the whole distribution, the existence and possibly the extent of downward nominal wage rigidity can be inferred if the deformation of the wage change distribution is stronger in low inflation than in high inflation years. In Beissinger and Knoppik (2001) we applied two approaches to the IABS data, the skewnesslocation approach of McLaughlin (1994) and the histogram-location approach of Kahn (1997), which both exploit the information contained in joint changes of shape and location of the wage change distribution. ${ }^{2}$ We analyzed the commonalties and differences of these ap-

1 There is, however, a strand of literature that seeks to provide theoretical explanations of downward nominal wage rigidity in a bargaining framework, for instance, MacLeod and Malcomson (1993), Holden (1994) and Holden (2001).

2 Applications of these approaches for US, Canadian and UK data include Lebow, Stockton and Washer (1995), McLaughlin (1999), Lebow, Saks and Wilson (1999), Christofides and Leung (2000), Christofides and Stengos (2000), McLaughlin (2000) and Nickell and Quintini (2001). 
proaches and pointed out that one must be careful in interpreting the results. ${ }^{3}$ This is because the validity of these approaches rests on the assumption that changes in the shape of the wage change distribution are solely caused by the interaction of downward nominal wage rigidity and location and not affected by other factors. However, this presumption can be criticized for two main reasons: First, the shape of the wage change distribution in different years also depends on the composition of the workforce, which may change. Second, changes in the shape of the wage change distribution may be obscured by measurement error. In survey data measurement error may be a problem due to erroneous reporting, whereas in social security data as in the IABS measurement error prevails because only information about earnings but not about hourly wages is available. In our former paper we dealt with the first problem by selecting a subsample of the data which was as homogenous as possible and we took account of the second point by emphasizing that our conclusions which confirmed the existence of downward rigidity referred to downward nominal earnings rigidity. Since measurement error may have obscured the true extent of wage rigidity, we suspected that the extent of downward nominal wage rigidity is even higher.

Direct evidence about downward nominal wage rigidity is clearly desirable. We therefore use an approach that is capable to deal with the two problems and to provide such direct evidence in this paper. It might be termed earnings-function approach, since its distinctive feature is that a number of variables (human capital, industry and aggregate) are used to explain wage changes or wages, thereby tackling the first problem. With regard to the second problem, Altonji and Devereux (1999) have suggested how to deal with the issue of measurement error. Other applications within the earning-functions approach include Fehr and Goette (2000) and Farès and Hogan (2000). Applications differ in i) their focus on wage changes or wages, ii) the treatment of measurement error, and iii) the specific assumptions on the nature of downward nominal wage rigidity.

Using a model for wage changes, our paper exhibits innovative features with regard to points ii) and iii) in suggesting to apply a more general modeling for the measurement error and in developing a model with proportional downward nominal wage rigidity which seems more in line with informal evidence on the nature of downward nominal wage rigidity, as reported in Bewley (1999). This specification allows us to directly estimate the share of wage cuts that are prevented by downward nominal rigidity. We also suggest new ways to examine the real implications of our estimates. For both, the historical experience and alternative inflation policies the resulting real wage wedge between notional and actual real wage is computed and used to infer the effects of downward nominal wage rigidity on the NAIRU under different inflation policies.

3 This is also true of the symmetry approach of Card and Hyslop (1997) which operates on a different principle, and is also discussed in Beissinger and Knoppik (2001). 
The remainder of the paper is organized as follows. In section 2 we present a model of wage changes under proportional downward nominal wage rigidity, including alternative specifications of measurement error. Section 3 provides information on the data used. Sections 4 and 5 present our estimation results and discuss their implications, respectively. In section 6 we suggest which conclusions can be drawn from our results.

\section{Model}

The log nominal wage change which would prevail in the absence of downward nominal rigidity is usually called notional or counterfactual wage change. In the following the random variable representing the counterfactual wage change for individual $i$ at time $t$ is denoted by $\Delta w_{i t}^{*}$. It is assumed that $\Delta w_{i t}^{*}$ can be explained by a set of variables arranged in a row vector $x_{i t}$ :

$$
\Delta w_{i t}^{*}=x_{i t} \beta+\varepsilon_{i t}, \varepsilon_{i t} \sim N\left(0, \sigma_{\varepsilon}^{2}\right),
$$

where $\beta$ is a column vector of parameters and $\varepsilon_{i t}$ denotes an i.i.d. normally distributed error term. The actual wage change $\Delta w_{i t}^{a}$ is equal to the notional wage change except in cases where the latter is negative and the person is affected by downward nominal wage rigidity. Whether this is the case is indicated by a random variable $D_{i t}$ which takes on the value one with probability $\rho$ if there is downward nominal wage rigidity and zero otherwise. This is therefore a model with proportional downward nominal wage rigidity, since a proportion $\rho$ of notional wage cuts will be prevented by rigidity; the degree of rigidity in the model is captured by the parameter $\rho$. Under proportional downward nominal wage rigidity the actual wage change takes on the following values:

$$
\Delta w_{i t}^{a}=\left\{\begin{array}{ccc}
x_{i t} \beta+\varepsilon_{i t} & \text { if } & x_{i t} \beta+\varepsilon_{i t} \geq 0 \\
0 & \text { if } & x_{i t} \beta+\varepsilon_{i t}<0 \wedge D_{i t}=1 \\
x_{i t} \beta+\varepsilon_{i t} & \text { if } & x_{i t} \beta+\varepsilon_{i t}<0 \wedge D_{i t}=0 .
\end{array}\right.
$$

It is our interpretation of the available interview studies that downward nominal wage rigidity is better captured by our model of proportional downward nominal wage rigidity than by the alternatives, threshold or absolute rigidity. ${ }^{4}$ In particular, proportional downward nominal wage rigidity takes account of the observation that cuts do happen, which is not the case under absolute downward nominal wage rigidity. Also, small and moderate size cuts do happen, which is not the case under a threshold downward nominal wage rigidity, at least not in its pure form. Additional advantages of the proportional model are that the proportion of wage cuts prevented by rigidity is directly estimated and that this functional form makes it directly

4 A recent example of these studies is Bewley (1999). Altonji and Devereux (1999) and Fehr and Goette (2000) use a threshold rigidity, where only those cuts whose absolute value exceeds a threshold will occur; Farès and Hogan (2000) use a model with absolute rigidity. 
comparable to the proportional model of the otherwise unrelated histogram-location approach. ${ }^{5}$

Because of the mass point at zero $\Delta w_{i t}^{a}$ has no density. Instead, we use a construct we call pseudo-density for graphical representation. The pseudo-density of $\Delta w_{i t}^{a}$ derives from the counterfactual density, but differs from it by thinning of its negative tail and pile up at zero. In FIGURE 1 it is shown how the extent of change in shape depends on the degree of rigidity $\rho$ and the value of the expected (notional) wage change $x_{i t} \beta$. In FIGURE $1 a$ the counterfactual density for given $x_{i t} \beta$ is depicted. In the presence of downward nominal wage rigidity desired wage changes are less likely if they require nominal cuts. A freeze of nominal wages is thought to occur instead. In FIGURE $1 b$ the associated thinning of the distribution below zero and the mass point at zero can be recognized. Obviously, for a given expected wage change $x_{i t} \beta$, these effects of downward nominal wage rigidity on the shape of the actual distribution are more pronounced if the rigidity parameter $\rho$ is high. The effects of downward nominal wage rigidity also depend on the location of the density which may be measured by $x_{i t} \beta$. A higher $x_{i t} \beta$ implies a lower probability for desired wage cuts. As a result, a smaller part of the left tail of the corresponding pseudo-density is negative and therefore affected by thinning, which leads to a smaller mass point at zero (see FIGURE 1c).

\section{Figure 1}

Measurement error may prevent actual wage changes to be directly observable, depending on the nature of the data available. In survey data this is caused by false or erroneous reporting of some respondents. As explained in more detail in the next section, the social security data used in this paper should hardly be affected by misreporting. Nevertheless, we have to deal with measurement error in our analysis since only information about observed changes in earnings, $\Delta y_{i t}$, but not on actual changes in wage rates is available. Observable changes in earnings can be interpreted as being the sum of changes in actual wage rates and a random variable $\mu_{i t}$ which captures variation in working hours, fringe benefits and more conventional measurement errors, i.e. $\Delta y_{i t}=\Delta w_{i t}^{a}+\mu_{i t}$. Together with equation (2) this leads to

$$
\Delta y_{i t}=\left\{\begin{array}{ccc}
x_{i t} \beta+\varepsilon_{i t}+\mu_{i t} & \text { if } & 0 \leq x_{i t} \beta+\varepsilon_{i t} \\
\mu_{i t} & \text { if } & x_{i t} \beta+\varepsilon_{i t}<0 \wedge D_{i t}=1 \\
x_{i t} \beta+\varepsilon_{i t}+\mu_{i t} & \text { if } & x_{i t} \beta+\varepsilon_{i t}<0 \wedge D_{i t}=0
\end{array} \quad \text { where } \operatorname{Pr}\left(D_{i t}=1\right)=\rho .\right.
$$

Along with the distribution of observable earnings changes also a distribution for counterfactual earnings changes can be defined. This is the distribution which results from the distribution of notional wage changes if measurement error prevails, but rigidity is absent:

$$
\Delta y_{i t}^{*}=\Delta w_{i t}^{*}+\mu_{i t} .
$$

5 Cf. Kahn (1997) and Beissinger and Knoppik (2001). 
To complete the model, the properties of $\mu_{i t}$ have to be specified. We consider three alternative types of measurement error giving rise to three variants of the model described in equation (3). Under the first specification the measurement error $\mu_{i t}$ is distributed normally, leading to the normal measurement error (NME) model of relative wage changes:

$$
\mu_{i t} \sim N\left(0, \sigma_{\mu}^{2}\right)
$$

Two alternative specifications of $\mu_{i t}$ are non normal, but contain normal building blocks. The first alternative is the mixed measurement error (MME) model of relative wage changes. The measurement error obeys 6

$$
\begin{aligned}
& \mu_{i t} \sim N\left(0, \sigma_{\mu}^{2}\right) \quad \text { with probability } 1-n \\
& \mu_{i t}=0 \quad \text { with probability } n \text {, }
\end{aligned}
$$

where $0 \leq n \leq 1$ is the share of observations that are measured exactly. In our context the MME model describes a situation where for some observations the relative change in earnings is solely brought about by the relative change in actual wages and not influenced by other factors as, for instance, variation in working hours. In addition to the NME and MME specifications of the measurement error, we consider a more elaborate alternative of the MME model in which a share $c$ of the observations affected by measurement error is characterized by a standard deviation $\sigma_{\mu c}$ instead of $\sigma_{\mu}$. Our intention behind estimating such a variant of the model is the description of a situation where a small share $c$ of the observations is measured very poorly. Hence, in the estimates it should turn out that $0 \leq c \ll 1$ and $\sigma_{\mu c}>\sigma_{\mu}$. Since the high dispersion error component can be interpreted to contaminate the sample, the respective model variant is called the contaminated mixed measurement error (CMME) model of relative wage changes. ${ }^{7}$ In this case the measurement error follows

$$
\begin{array}{ccc}
\mu_{i t} \sim N\left(0, \sigma_{\mu}^{2}\right) & \text { with probability } & 1-n-c \\
\mu_{i t} \sim N\left(0, \sigma_{\mu c}^{2}\right) & \text { with probability } & c \\
\mu_{i t}=0 & \text { with probability } & n .
\end{array}
$$

The extent of measurement error varies along the two dimensions dispersion, which is captured by the parameter $\sigma_{\mu}$ (and $\sigma_{\mu c}$ ) and coverage, which is determined by the parameters $n$ in the MME model and $n$ and $c$ in the CMME model. The implications with respect to coverage for the shape of the distribution of relative earnings changes for the MME model are illustrated in FIGURE 2. The plots in the columns of FIGURE 2 differ by the share $n$ of observations, that are not affected by measurement error. $n$ decreases from $n=1$ in column a), where all observations are measured correctly, to $n=0$ in column d), where all observations are affected by measurement error. In the limiting cases of columns a) and d), the MME model be-

6 A mixed measurement error of this type has been suggested by Altonji and Devereux (1999).

7 Johnson and Kotz (1970), p. 87, briefly discuss such a type of contamination component in a normal distribution. In our estimations no restriction is imposed on the parameters $\sigma_{\mu}, \sigma_{\mu c}, c$ and $n$. 
comes equivalent to model (2) and the NME model, respectively. The plots in the rows of FIGURE 2 demonstrate how the shape of the observable distribution of earnings changes $\Delta y_{i t}$ (strong line) is influenced by shifts in location, with the most leftward distribution in the first row, and the most rightward distribution in the last row. For reference, each plot of FIGURE 2 also contains a plot of counterfactual earnings changes $\Delta y_{i t}^{*}$ (thin line). Because of the absence of measurement error, the counterfactual and observable distributions of earnings changes in column a) coincide with the respective distributions of wage changes, thus providing a further example of the joint variation of shape and location under downward nominal wage rigidity which was already illustrated in FIGURE 1. From columns a) to d) the coverage and therefore the overall extent of measurement error increases. This has several noteworthy consequences: first, for given locations, the counterfactual and factual earnings distributions are getting more spread out, with flatter peaks and thicker tails. Second, the extent of thinning below zero and the spike at zero are reduced with the increase in coverage of the measurement error. The reason is that measurement error shifts some probability mass from above zero and zero to the range below zero. Third, if the share of observations affected by measurement error is high, the change in the shape of the distribution due to a change in location is hardly discernible (compare columns (c) and (d) with columns (a) and (b)). In this case methods which rely on joint variation of shape and location for the identification of downward nominal wage rigidity will massively understate the extent of true DWNR in wages if measurement error is not modeled.

\section{FIGURE 2}

Before we turn to the estimation results obtained for the various models and to their implications, we give a brief introduction to our data in the following section.

\section{Data}

Our analysis is based on the IAB-Beschäftigtenstichprobe (IABS) covering the period from 1975 to $1995 .^{8}$ The IABS is a $1 \%$ random sample drawn from the German social security accounts which represents one of the most important data sources for labor market research in Germany. Due to the social insurance procedure introduced in 1973 employers are obliged to report at least once a year all earnings for those employees who are subject to compulsory social insurance. The earnings data in the IABS refer to gross earnings excluding employer's contributions to social security but including all kinds of fringe benefits. The greatest advantage of the IABS is the high reliability of the earnings data due to plausibility checks that are performed by the social security institutions and legal sanctions for misreporting. Contrary to most other studies based on survey data, measurement error due to false or erroneous report-

8 In 1999 this dataset has been made available for scientific use by the research institute of the Federal Employment Service ('Institut für Arbeitsmarkt- und Berufsforschung', IAB). See Bender, Haas and Klose (2000) for a description of the new version of the IABS. 
ing is therefore not a problem in our analysis. However, as explained in appendix A, there are also some drawbacks of the dataset, namely the censoring of the earnings distribution, a structural break in the earnings measure in 1984, the truncation of gross daily earnings to integer values and the lack of information about hours worked.

The focus of our study are year-to-year changes of log earnings that are computed on the individual level for full-time male employees working in the western part of Germany. The data selection is explained in more detail in appendix A and can be summarized as follows: We restrict the analysis to ,job stayers“, i.e. employees who remained at the same employer for two consecutive years for the full length of time. We only take skilled and unskilled employees into account, whereas high-skilled employees are excluded. We also restrict the sample to employees being at least 25 and at most 65 years old. Furthermore we consider only workers and salaried employees in manufacturing and services, which comprise 34 industries. We only use those observations that include information about firm size and thereby loose the 1975/76 changes. Due to our data selection we are left with a total of 734,827 observations of year-toyear log earnings changes for the sample period 1976-1995, with 590,570 observations for workers and 144,257 observations for salaried employees.

\section{Empirical implementation and results}

In this section we discuss the results obtained by estimating the model of proportional downward nominal wage rigidity described in equation (3). Prior to estimation, the human capital, industry and aggregate variables which determine the notional wage change have to be specified. We include the variable experience in the equation for the notional wage change and expect a negative sign in the estimation, since it is well-known that there is a positive and concave functional relationship between earnings levels and experience. We also include experience squared to allow for "higher-order non-linearity" in the earnings-experience relationship. Furthermore, we add controls for education, marital status, firm size and nationality. We include industry dummies to take account of the fact that notional wage changes among industries may differ due to differences in productivity growth or the wage-setting process. Relative wage changes may also be affected by changes in the employment shares of industries, reflecting declining and expanding industries. We therefore include the relative change in the employment share (in total employment) of each industry and expect a positive sign for the respective estimate. We add the inflation rate and lagged inflation rates to the equation since individual nominal wage changes depend on expected inflation. Furthermore, we include the change (and lagged changes) of the aggregate unemployment rate because a rise in aggregate unemployment will constrain wage growth. A dummy variable for 1984 controls for the structural break that occurred in that year due to a change in earnings reports, see appendix A.

As outlined in section 2, alternative assumptions about the measurement error lead to the NME, MME and CMME variants of the model. We computed separate maximum likelihood estimates for wage and salary earners, since wage formation for both groups of employees is 
quite different. A detailed derivation and discussion of the likelihood functions is found in Knoppik (2001). TABLE 1 reports the estimates for the key parameters of the downward nominal wage rigidity model, whereas the complete estimation results are delegated to appendix B. In all estimated model variants we obtain a high and highly significant value of $\rho$. For workers this value varies between 0.46 and 0.72 and for salaried employees between 0.58 and 0.91 . Taking the estimates for salaried employees as an example, our results imply that at least 58 percent (and possibly up to 91 percent) of all notional wage cuts are prevented by downward rigidity. Hence, our results indicate the presence of substantial downward nominal wage rigidity in the data.

\section{TABLE 1}

Since the estimated values of $\rho$ differ between the model variants, a discussion of the relative merits of the different specifications seems in order. In the NME model it is assumed that all wage change observations are affected by measurement error. This implies that the probability of observing earnings freezes is zero, which is clearly at odds with the spike at zero in the empirical earnings change distribution. Therefore, the NME model does not represent the best strategy for estimating the extent of downward nominal wage rigidity. The two models with mixed measurement specifications, MME and CMME, are well suited to reconcile the observed spike at zero with the theoretical properties of the models. In both cases a fraction of zero observations in the earnings change distribution represents exactly measured wage freezes. The absence of measurement error for a fraction of employees seems plausible, since there will always be some who have identical incomes in two consecutive years. The MME model is a special case of the more general CMME model $(c=0)$ and the choice between the two can therefore be based on their log likelihoods. ${ }^{9}$ The likelihood ratio test reveals that the CMME model is a better description of the data which makes it our preferred specification. As a result, we put the strongest weight on the estimated degrees of rigidity of $\rho=0.68$ for workers and $\rho=0.91$ for salaried employees.

A closer look at the results reported in TABLE 1 shows that along with the estimate for $\rho$ also the estimates for $\sigma_{\varepsilon}$ and $\sigma_{\mu}$ vary with the chosen model variant. In the NME model the estimated standard deviation of the error term of the notional wage change equation ("wage change error term') is roughly twice the standard deviation of the measurement error. This ratio between estimated standard deviations is roughly inverted for the MME and CMME models. The reason for these differences is related to the fact that the NME model on the one hand and the MME and CMME models on the other hand deal differently with the spike at zero in the observed earnings change distribution. In the NME model the presence of zero earnings changes must lead to a low estimated standard deviation of the measurement error $\sigma_{\mu}$. Correspondingly a relatively high estimate of the standard deviation $\sigma_{\varepsilon}$ is obtained, since $\sigma_{\varepsilon}$ must account for the width of the earnings change distribution which is not ex-

9 Because of the mass points in the MME and CMME models their likelihood values cannot directly be compared with those of the NME model. 
plained by the variables contained in the vector $x$. In the MME and CMME models the zero earnings changes are interpreted as exactly measured observations. These observations therefore do not prevent (as they do in the NME model) an appropriate decomposition of total variation into $\sigma_{\mu}$ and $\sigma_{\varepsilon}$; for both models a rather high estimated $\sigma_{\mu}$ and a rather low estimated $\sigma_{\varepsilon}$ result. For the CMME model, 1.4 percent (1.7 for salary earners) of all observations are affected by the "contamination" measurement error with a much higher dispersion and an estimated standard deviation of $\sigma_{\mu c}=0.24$. This explains why the "standard" measurement error has a lower standard deviation $\sigma_{\mu}$ in the CMME model than in the MME model, where the single measurement error term seems to be an average of the "standard" and "contamination " measurement error terms. A further effect of the differentiated modeling of the measurement error in the CMME model is to further reduce estimated $\sigma_{\varepsilon}$, which is accompanied by higher estimated $\rho$ to explain the observed freezes.

In the discussion of measurement error in section 2 we demonstrated that for sufficiently strong measurement error the shape of the observable distribution of earnings and the joint variation of location and shape under downward nominal wage rigidity are substantially affected by the presence of measurement error. Under such circumstances the true degree of rigidity will be hidden behind measurement error, at least to some extent. Our results do show that the measurement error $\mu$ is of the same order of magnitude as the wage error $\varepsilon$. In order to demonstrate how strongly this affects estimates of $\rho$ that ignore measurement error, we present parameter estimates from a composite error model with the same specification as our earlier models, with one exception: measurement error is completely ignored. We use the term composite error (rather than 'no measurement error') to emphasize that the single error term $\eta$ will contain unexplained wage variation and measurement error. The composite error model is described by $\Delta y_{i t}^{*}=x_{i t} \beta+\eta_{i t}$ and

$$
\Delta y_{i t}=\left\{\begin{array}{ccc}
x_{i t} \beta+\eta_{i t} & \text { if } & 0<x_{i t} \beta+\eta_{i t} \\
0 & \text { if } & x_{i t} \beta+\eta_{i t}<0 \wedge D_{i t}=1 \\
x_{i t} \beta+\eta_{i t} & \text { if } & x_{i t} \beta+\eta_{i t}<0 \wedge D_{i t}=0
\end{array} \quad \text { where } \operatorname{Pr}\left(D_{i t}=1\right)=\tilde{\rho} .\right.
$$

TABLE 2 shows selected estimated parameters from the composite error model for wage and salary earners. Estimated degrees of apparent rigidity $\tilde{\rho}$ are much lower than in any of the models with measurement error and are less than $40 \%$ of the estimates of $\rho$ in the CMME model.

\section{Table 2}

These findings also shed some light on the results in Beissinger and Knoppik (2001). The values found using the modified histogram-location approach are reproduced in row (5) of TABLE 2. The "earnings rigidity" analyzed in that paper is effectively what is captured by the "apparent" degree of rigidity $\tilde{\rho}$ in the composite error model. The values of $\tilde{\rho}$ and $\rho_{\Delta y}$ are almost identical and corroborate our earlier conjecture that the relatively low degrees of earnings rigidity are due to the neglected role of measurement error and hours variation in the his- 
togram-location approach. In Beissinger and Knoppik (2001) it was also found that the degree of earnings rigidity depends on business cycle conditions and it was suspected that the importance of variable earnings components may have increased after 1984. For that reason we also estimated versions of the CMME model with year specific degree of rigidity $\rho$ and 1984-95 dummies for the measurement error parameters. We found a dependence of downward nominal wage rigidity on business cycle conditions as proxied by changes in the rate of unemployment. The hypothesis of increased volatility was also confirmed. Since the key parameters of the model remain essentially unchanged, and because of space limitations we do not present these results in detail.

\section{Implications}

Our specification directly yields the proportion $\rho$ of nominal wage cuts that are prevented by downward nominal wage rigidity. In this section we explore several further implications of our estimates, and are able to answer the following questions: How many observations in the sample were affected by downward nominal wage rigidity? How does the share of affected observations depend on the rate of inflation? And, what are the effects of the estimated degree of downward nominal wage rigidity on long-run unemployment under different rates of inflation?

\section{Extent of downward nominal wage rigidity in the sample}

The estimated degree of downward nominal wage rigidity $\rho$ only allows a statement that is conditional on the occurrence of notional cuts. But our results also enable us to evaluate how likely notional cuts were, and therefore how likely it was to be affected by downward nominal wage rigidity individually, or which share of observations was affected by downward nominal wage rigidity in the aggregate. Since the expected values of individual notional wage changes were estimated, the corresponding cumulative distribution functions can be used to calculate the probability $r_{i t}$ of a wage freeze for each individual, in a given period:

$$
r_{i t}=\hat{\rho} \operatorname{Pr}\left(\Delta w_{i t}^{*}<0\right)=\hat{\rho} \Phi\left(-x_{i t} \hat{\beta} / \hat{\sigma}_{\varepsilon}\right)
$$

where $\Phi($.$) is the cumulative distribution function of the standard normal distribution. The$ estimated individual freeze probabilities are a function of the estimated parameters and the individual regressor values, $r_{i t}=r\left(x_{i t} \hat{\beta}, \hat{\sigma}_{\varepsilon}, \hat{\rho}\right)$. If averaged over all $N$ observations in the sample, the share of observations $R$ affected by downward nominal wage rigidity is estimated:

$$
R=\frac{1}{N} \sum_{t} \sum_{i} r\left(x_{i t} \hat{\beta}, \hat{\sigma}_{\varepsilon}, \hat{\rho}\right)
$$

Values of $R$ for the three models for wage and salary earners are found in TABLE 3. For the MME and CMME models the shares of those affected by downward nominal wage rigidity appear to be rather low, with only between 4.9 and 7.3 percent of the observations affected by 
downward nominal wage rigidity. The values resulting from the NME models, 21.8 percent for workers and 17.5 percent for salary earners are much higher. However, for the reasons explained above, we are convinced the NME model misrepresents the situation.

\section{TABLE 3}

The explanation for the relative small values of $R$ is that while there are several low inflation years in the sample period, average inflation over these years was slightly above three percent. This was high enough to prevent more widespread effects of downward nominal wage rigidity. It is an important question, how pervasive downward nominal wage rigidity becomes with still lower rates of inflation. To answer this question, we will now calculate shares of affected observations, sweep-up of individual wage growth and the real wage wedge for different rates of inflation.

\section{Role of inflation for individual and aggregate real wages}

One of the determinants of the effects of downward nominal wage rigidity are the individual expected values of the notional wage changes, which depend on current and lagged rates of inflation. In order to explore the steady-state effects of different rates of inflation, $x_{i t}$ and $\beta$ are reduced to $\tilde{x}_{i t}$ and $\tilde{\beta}$ by dropping current and lagged inflation and current and lagged changes in unemployment. The expected values of individual notional wage growth that would result under some rate of inflation $\pi$ in the long run are then given by $\tilde{x}_{i t} \hat{\tilde{\beta}}+\pi .10$ Hence, the shares of affected observations $R$ for different rates of inflation can be calculated as:

$$
R(\pi)=\frac{1}{N} \sum_{t} \sum_{i} r\left(\tilde{x}_{i t} \hat{\tilde{\beta}}+\pi, \hat{\sigma}_{\varepsilon}, \hat{\rho}\right)
$$

Values of $R(\pi)$ for the three models for workers and salary earners for rates of inflation from zero to five percent are found in TABLE 3. At zero inflation the shares of those affected by downward nominal wage rigidity would be much higher than they were under the actual inflation experience during the sample period. For the CMME and MME models they range from 14.3 to 20.65 percent (31.4 and 28.8 for the NME model). As an example, for the CMME model of salary earners the way in which the share of affected employees depends on the rate of inflation is summarized by a plot in panel a) of FIGURE 3. The effect of downward nominal wage rigidity is significant for rates of inflation below three percent, and negligible above five percent.

\section{FIGURE 3}

10 The homogeneity constraint on current and lagged inflation in our specification ensures that steady-state inflation enters with a coefficient of one. 
Next we calculate the difference between expected actual wage change and expected notional wage change, the so called sweep-up, which is caused by the prevented wage cuts. Individual sweep-up is defined as:

$$
\begin{aligned}
s u_{i t} & =E \Delta w_{i t}^{a}-E \Delta w_{i t}^{*} \\
& =\hat{\rho}\left[\hat{\sigma}_{\varepsilon} \phi\left(\mu_{i t} / \hat{\sigma}_{\varepsilon}\right)+\mu_{i t} \Phi\left(\mu_{i t} / \hat{\sigma}_{\varepsilon}\right)-\mu_{i t}\right],
\end{aligned}
$$

where the expected notional wage change $\mu_{i t}$ is either equal to $x_{i t} \hat{\beta}$ or to $\tilde{x}_{i t} \hat{\tilde{\beta}}+\pi$, depending on the question at hand. Individual sweep-up is a function of the expected notional wage change and the estimated parameters, $s u_{i t}=s u\left(\mu_{i t}, \hat{\sigma}_{\varepsilon}, \hat{\rho}\right)$. Aggregate sweep-up is obtained by averaging over observations:

$$
S U=\frac{1}{N} \sum_{t} \sum_{i} s u\left(\mu_{i t}, \hat{\sigma}_{\varepsilon}, \hat{\rho}\right)
$$

Values of aggregate sweep-up for the three models for wage and salary earners for rates of inflation from zero to five percent and for the sample are presented in TABLE 3. At zero inflation sweep-up ranges from 0.3 to 0.4 additional percentage points of individual expected wage growth for the CMME and MME models (1.5 and 1.2 for the NME model), depending on specification and type of employee. ${ }^{11}$

Not only does downward nominal wage rigidity increase individual expected wage growth, but it also introduces a real wage wedge between the aggregate actual and notional real wage levels. Downward nominal wage rigidity does not, however, introduce additional aggregate wage growth. The expected aggregate relative real wage wedge RWW is defined as:

$$
R W W=E\left[\frac{1}{N} \sum_{t} \sum_{i} w_{i t}^{a}-\frac{1}{N} \sum_{t} \sum_{i} w_{i t}^{*}\right] .
$$

In the case of the policy experiments, the real wage wedge is a function of inflation, $R W W(\pi)$. It can be shown that sweep-up and real wage wedge are of the same size, by inserting equation (12) in equation (13).

$$
\begin{aligned}
S U & =\frac{1}{N} \sum_{t} \sum_{i}\left(E\left(w_{i t}^{a}-w_{i, t-1}^{a}\right)-E\left(w_{i t}^{*}-w_{i, t-1}^{a}\right)\right) \\
& =\frac{1}{N} \sum_{t} \sum_{i}\left(E\left(w_{i t}^{a}\right)-E\left(w_{i t}^{*}\right)\right)=R W W .
\end{aligned}
$$

11 Note that median notional expected wage growth ranges from 1.76 to 2.09 percent for the CMME and MME models (0.98 and 1.63 for the NME model). 


\section{Real effects of downward nominal wage rigidity}

In order to assess the effects of the real wage wedge generated by downward nominal wage rigidity on the long-run rate of unemployment, a modified Phillips curve specification as proposed by Akerlof, Dickens and Perry (1996) is used:12

$$
\pi_{t}=\pi_{t}^{e}+a\left(u^{L S}-u_{t}\right)+s_{t} .
$$

$\pi_{t}$ and $\pi_{t}^{e}$ denote the rate of inflation and the expected rate of inflation, $u_{t}$ and $u^{L S}$ are the rate of unemployment and the lowest sustainable rate of unemployment, and $s_{t}$ is the real wage wedge relative to the level of the real wage. Except for the presence of $s_{t}$, equation (16) is a typical bare-bones Phillips curve specification for annual data: If current unemployment is one percentage point below the lowest sustainable rate of unemployment for one year, this will raise the rate of inflation by $a$ percentage points. Positive values of $s$ will require increased unemployment of $\Delta u=a \cdot s$ if inflation is not to increase. The long-run version of equation (16) allows us to calculate the non-accelerating inflation rate of unemployment NAIRU, $u^{N A I}$ :

$$
u^{N A I}=u^{L S}+\frac{1}{a} s(\pi ; .)
$$

The NAIRU exceeds the lowest sustainable rate of unemployment when the relative real wage wedge variable $s$ is greater than zero. If downward nominal wage rigidity prevails, this will be the case for low rates of inflation. Equation (17) therefore describes a non-linear long-run Phillips curve. Since from our estimation results we already have computed steady-state values for the relative real wage wedge for different values of the rate of inflation, $R W W(\pi)$, excess long-run unemployment as a function of inflation $u^{X S}(\pi)$ can be calculated as: ${ }^{13}$

$$
\begin{aligned}
u^{X S}(\pi) & =u^{N A I}(\pi)-u^{L S} \\
& =\frac{1}{a} R W W(\pi),
\end{aligned}
$$

where the only information still needed is an estimate of the parameter $a$, which measures how strongly inflation reacts to deviations from the lowest sustainable unemployment rate. Recent estimates of $a$ for Germany in Franz (2001) range from 0.2 to $0.5 .{ }^{14}$ For the computation of excess unemployment $u^{X S}$ we have used $a=.4$; estimates of $u^{X S}$ for the three models for wage and salary earners for rates of inflation from zero to five percent are found in TABLE 3. At zero inflation downward nominal wage rigidity causes additional long-run unemployment in a range from .74 to 1.02 percentage points in the CMME and MME models (3.85 and 2.92 percentage points in the NME model). This long-run adverse effect on unemploy-

12 We use $s_{t}$ instead of $\beta /(\beta-1) S_{t}$ in the original notation to denote the relative real wage wedge RWW. A detailed discussion of the Phillips curve in Akerlof, Dickens and Perry (1996) is found in Knoppik (1999).

13 In making this calculation it is assumed that the subsample in question is typical of the whole economy.

14 Franz (2001) uses quarterly data; his parameter estimates therefore had to be multiplied by four. Note that the range for $a$ of $0.2 \ldots 0.5$ roughly coincides with the range of $a=0.3 \ldots 0.6$ that is reported by Stiglitz (1997), p. 5 as a stylized fact for the US. 
ment of low rates of inflation is illustrated in a plot of the long-run Phillips curve in panel b) of FIGURE 3.

It may come as a surprise that the zero inflation NAIRU is only around one percentage point higher than the NAIRU at higher rates of inflation, given the high degree of estimated nominal wage rigidity and bearing in mind the results of Akerlof, Dickens and Perry (1996) who have found an increase of several percentage points. However, this result can be easily explained: The estimated expected (notional) wage changes at zero inflation are on average positive, with means and medians around two percent. Some of this may be due to aggregate productivity growth, but in our interpretation individual wage growth over the course of a career also plays a major role. Together with the fact that the expected wage changes and the error term in the wage equation both have rather small standard deviations, this means that even at zero inflation only a relatively small part of the notional wage change distribution implies desired wage cuts and is affected by downward nominal wage rigidity. This consideration also explains the relatively small shares of affected observations at zero inflation, $R(0)$.

\section{Concluding remarks}

In this paper we analyzed the evidence and real implications of downward nominal wage rigidity in Germany by using the IAB-Beschäftigtenstichprobe which represents the largest and most reliable data source of German income data. Our model of proportional downward nominal wage rigidity, which is formulated for observable individual earnings changes, takes account of desired wage changes and their determinants as well as measurement error including hours variation. We presented maximum likelihood estimates separately for wage and salary earners for alternative specifications of measurement error. The degree of downward nominal wage rigidity, which is reflected in the share of prevented wage cuts, is directly estimated and turns out to be substantial: According to our preferred specification around 70 percent of wage earners and 90 percent of salary earners who are due for wage reductions obtain wage freezes instead. We also demonstrated that the neglect of measurement error generates estimates of earnings rigidity which are 60 percent lower than our estimates of wage rigidity. These estimates closely match our earlier results in Beissinger and Knoppik (2001) where earnings rigidity was directly estimated by an unrelated method, the histogram-location approach. We see both lines of analysis supported by this correspondence. At the same time it highlights the potential pitfalls of trying to directly draw conclusions on wage rigidity with approaches that eschew an explicit treatment of measurement error.

In order to explore the implications of our estimates, shares of affected individuals and the increase in individual expected wage growth were calculated for the historical inflation experience over the sample period and for alternative inflation policies. The variation of inflation policy showed that the effects of downward nominal wage rigidity become sizable for rates of inflation that are lower than three percent and are negligible for rates of inflation above four percent. We also tried to assess the effects of downward nominal wage rigidity on 
equilibrium unemployment. According to our results, a zero inflation policy will cause one percentage point of excess unemployment, i.e. the NAIRU would be one percentage point higher than the lowest sustainable rate of unemployment. Given the high degree of wage rigidity this seems to be a relatively moderate increase. However, it can be explained by the narrow estimated notional wage change distribution, which even at zero inflation on average requires two percent individual wage growth.

Over the last few decades Germany has had the most favorable inflation record of all large industrial nations, but by no means an impeccable one. While there is a zero inflation episode in the sample period, some uncertainty remains whether attitudes towards nominal wage cuts remain unchanged under permanent zero inflation. For this reason our results constitute no definite proof of the role of downward nominal wage rigidity in a zero inflation environment. Nevertheless, they take the theoretical argument of potential adverse effects of very low inflation quite a step further by specifically showing the existence of downward nominal wage rigidity in the largest European economy, finding its extent to be substantial and demonstrating that a very low inflation policy might indeed be a rather costly endeavor.

\section{Appendix A: Data selection}

In the IABS there is no information about hours worked except for the information about parttime or full-time status. It is therefore not possible to compute hourly wages. Since changes of part-time to full-time work or vice versa do not lead to a new report of the employer, there is the possibility that temporary transitions to part-time work during the course of the year are not documented in the annual report. According to the IAB this leads to some implausible changes in annual earnings for female employees, for whom part-time work is much more common. For that reason we restrict our analysis to full-time employed males working in the western part of Germany. We only consider ,job stayers“, i.e. employees who remained at the same employer for two consecutive years for the full length of time. We exclude "movers", i.e. persons who changed the employer, since interpretation of the behavior of movers is much less clear-cut than for stayers. The main reason is that movers consist of two groups, employees who were dismissed involuntarily and employees who voluntarily change the employer.

Earnings in the IABS are right-censored at the contribution assessment ceiling ('Beitragsbemessungsgrenze'). If (monthly) earnings are higher than this threshold, actual earnings will be unknown. Since for employees whose earnings are censored the growth rate of earnings can not be computed correctly, the censored records are removed from the dataset. However, this leads to a substantial change in the skill structure of our sample. Since high-skilled employees are no longer properly represented in the sample, they are completely removed from the dataset. Our analysis is therefore confined to unskilled and skilled male employees. The unskilled are defined as persons without vocational training. These are persons with a lower schooling level and no further occupational qualifications completed; this group includes lower secon- 
dary school (Hauptschule) and intermediate secondary school (Realschule) graduates who did not complete an apprenticeship or graduate from a full-time vocational school. The skilled are defined as persons with vocational training. These are persons with an occupational qualification, which might be either a completed apprenticeship or graduation from a vocational school.

In the IABS fringe benefits cannot be separated from 'regular' earnings. This is of importance since, starting in 1984, one-time payments to the employees have been subject to social security taxation and are therefore included in the earnings report of the employer. Before that date the inclusion of fringe benefits was voluntary. Steiner and Wagner (1996) analyzing the first version of the IABS note that this results in a structural break in the earnings data in 1984 which mainly affects the upper part of the earnings distribution. The possibility of a structural break has to be taken into account in our analysis. A structural break of this type directly leads to a level effect that affects the 1983-84 log earnings changes. Observations before that date should be valid, since if some employers reported fringe benefits before 1984 and others did not, it is very likely that employers usually were consistently using a single kind of reporting behavior. All observations after that date derive from correctly reported figures. However, it cannot be ruled out that the additionally included compensation components are more volatile than basic pay. This may indirectly have increased the volatility of earnings changes from 1984 onwards. A further problem that is relevant in the context of our analysis is caused by the fact that in the IABS the gross daily earnings variable has been truncated to integer values, which affects very small earnings changes. We therefore do not attempt to reach conclusions about the existence of menu cost effects.

We further restricted the sample to the manufacturing and service sector. ${ }^{15}$ Taking account of the anonymisation procedure of the IAB, we aggregated the IABS industry information to 34 industries which correspond to the national accounts classification. In this sample we detected some implausible high growth rates of (annual) earnings lying between 100 and 400 percent, which are concentrated in the group of employees being younger than 25 years. We suspect that this is due to a false coding in the variable describing the occupational status. In this variable both the apprenticeship and the full-time/part-time distinction are coded. It is therefore possible that an apprentice is incorrectly classified as a full-time worker. After the apprenticeship the respective person will probably earn more than double the previous income. To guarantee that these effects are not at work in our data, we restrict the sample to employees who are at least 25 years old. ${ }^{16}$ For our estimates we also use information about firm size. Unfortu-

15 Hence employees working in the following sectors were excluded: agriculture, mining, energy, the government sector and private organizations. Furthermore we excluded the employees from the eastern part of Germany who were working in the western part of Germany and the employees who were insured by the so-called „Knappschaft“".

16 The upper limit of 65 years is implied by the IABS. 
nately, the requirement that the firm size information must not be missing leads to the exclusion of all 1975 to 1976 wage change observations; all other years are barely affected. ${ }^{17}$

In our analysis we also use several aggregate time series. The inflation variable is based on the consumer price index for all private households. The unemployment rate refers to the total labor force. These series are taken from Sachverständigenrat zur Begutachtung der Gesamtwirtschaftlichen Entwicklung (1997). The industry employment data are taken from the national accounts of the Statistisches Bundesamt Deutschlands (Federal statistical office), Beschäftigtensegment 917.

\section{Appendix B: Complete Results}

Complete results are found in TABLE B.1 and TABLE B.2.

TABLE B.1

TABle B.2

17 We also excluded apprentices and employees working at home. Furthermore we requested that the information with respect to marital status, number of children, occupational status, training degree, occupation, nationality, industry affiliation and identification number of the respective firm are not missing. We examined whether the exclusion of missing values has led to a biased employment or industry structure but could not find evidence for this hypothesis. We also excluded records with overlapping employment spells, because there is no information about the number of hours worked in each of these jobs. 


\section{References}

Akerlof, G. A.; Dickens, W. T. and Perry, G. L. (1996), The Macroeconomics of Low Inflation [including comments by Gordon and Mankiw], in: Brookings Papers on Economic Activity, (1), 1-59 [60-76].

Altonji, J. G. and Devereux, P. J. (1999), The Extent and Consequences of Downward Nominal Wage Rigidity, NBER Working paper series 7236.

Beissinger, T. and Knoppik, C. (2001) Downward Nominal Rigidity in West-German Earnings 1975-1995, in: German Economic Review, 2(4), forthcoming.

Bender, S., Haas, A. and Klose, C. (2000), IAB Employment Subsample 1975-1995 - Opportunities for Analysis Provided by the Anonymised Subsample, IZA Discussion paper 117, February.

Bewley, T. F. (1999), Why wages don't fall during a recession, Cambridge, MA, Cambridge University Press.

Card, D. and Hyslop, D. (1997), Does Inflation "Grease the Wheels of the Labor Market"? [incl. comment by Shea], in: Romer, C. D. and Romer, D. H. (eds.), Reducing Inflation - Motivation and strategy, Chicago, London, University of Chicago Press, 71-114 [114-122].

Christofides, L. N. and Leung, M. T. (2000), Wage Adjustment in Contract Data: Wage Rigidity and Menu Costs, University of Guelph, July, mimeo.

Christofides, L. N. and Stengos, T. (2000), The Symmetry of the wage-change distribution: Non-parametric tests using contract and survey data, University of Guelph, July, mimeo.

Farès, J. and Hogan, S. (2000), The Employment Costs of Downward Nominal Wage Rigidity, Bank of Canada Working Paper 00/1.

Fehr, E. and Goette, L. (2000), Robustness and Real Consequences of Nominal Wage Rigidity, IERE Working Paper Series 44, Mai.

Franz, W. (2001), Neues von der NAIRU?, in: Jahrbücher für Nationalökonomie und Statistik, 221(3), $256-284$.

Holden, S. (1994), Wage bargaining and nominal rigidities, European Economic Review, 38, 1021-1039.

Holden, S. (2001), Monetary policy and nominal rigidities under low inflation rates, CESIFO working paper 481, May.

Johnson, N. L. and Kotz, S. (1970), Distributions in statistics - Continuous unvariate distributions vol. 1+2, New York et al., John Wiley \& Sons.

Kahn, S. (1997), Evidence of Nominal Wage Stickiness from Microdata, in: American Economic Review, 87(5), 993-1008.

Knoppik, C. (1999), Empirical macroeconomics of low inflation and the role of limits to nominal wage rigidity, Regensburger Diskussionsbeiträge zur Wirtschaftswissenschaft 332, September.

Knoppik, C. (2001), Models with Censoring and Measurement Error, University of Regensburg, June, mimeo.

Lebow, D. E., Saks, R. E. and Wilson, B. A. (1999), Downward Nominal Wage Rigidity: Evidence from the Employment Cost Index, Board of Governors of the Federal Reserve System - Finance and Economics Discussion Series 99/31, July.

Lebow, D. E., Stockton, D. and Washer, W. (1995), Inflation, Nominal Wage Rigidity, and the Efficiency of Labor Markets, Board of Governors of the Federal Reserve System - Finance and Economics Discussion Series 95-45, October.

MacLeod, W. B. and Malcomson, J. M. (1993), Investments, holdup, and the form of market contracts, in: American Economic Review, 83(4), 811-837.

McLaughlin, K. J. (1994), Rigid Wages?, in: Journal of Monetary Economics, 34(December), 383-414.

McLaughlin, K. J. (1999), Are Nominal Wage Changes Skewed Away From Wage Cuts? [incl. comment by Startz], in: Federal Reserve Bank of St. Louis Review, May, 117-132 [133-136].

McLaughlin, K. J. (2000), Asymmetric Wage Changes and Downward Nominal Wage Rigidity, Hunter College Graduate School, October, mimeo.

Nickell, S. and Quintini, G. (2001), Nominal Wage Rigidity and the Rate of Inflation, Center for Economic Performance Discussion Paper Series, March.

Sachverständigenrat zur Begutachtung der Gesamtwirtschaftlichen Entwicklung (1997), Wachstum, Beschäftigung, Währungsunion - Orientierungen für die Zukunft.

Steiner, V. and Wagner, K. (1996), Has Earnings Inequality in Germany Changed in the 1980's?, ZEW Discussion Paper 96-32.

Stiglitz, J. E. (1997), Reflections on the Natural Rate Hypothesis, in: Journal of Economic Perspectives, 11(1), 310.

Tobin, J. (1972), Inflation and Unemployment, in: American Economic Review, 62(1), 1-18. 


\section{Tables in order of appearance in text}

TABLE 1: Selected parameter estimates

\begin{tabular}{crrrrrr} 
& \multicolumn{3}{c}{ Wage earners } & \multicolumn{3}{c}{ Salary earners } \\
& $\begin{array}{c}\text { NME } \\
\text { a) }\end{array}$ & $\begin{array}{c}\text { MME } \\
\text { b) }\end{array}$ & $\begin{array}{c}\text { CMME } \\
\text { c) }\end{array}$ & $\begin{array}{c}\text { NME } \\
\text { d) }\end{array}$ & $\begin{array}{c}\text { MME } \\
\text { CMME }\end{array}$ & f) \\
\hline$\rho$ & 0.72 & 0.46 & 0.68 & 0.79 & 0.58 & 0.91 \\
$\sigma_{\varepsilon}$ & 6.5 & 3.6 & 3.2 & 5.7 & 3.1 & 2.7 \\
$\sigma_{\mu}$ & 2.9 & 10.1 & 7.5 & 2.6 & 11.6 & 6.7 \\
$n$ & - & 0.73 & 0.60 & - & 0.83 & 0.68 \\
$\sigma_{\mu c}$ & - & - & 24.1 & - & - & 25.9 \\
$c$ & - & - & 0.014 & - & - & 0.017 \\
$\ln L$ & 817142.5 & 722157.5 & 729258.4 & 214936.4 & 209839.2 & 212789.4 \\
$N$ & 590570 & 590570 & 590570 & 144257 & 144257 & 144257 \\
\hline
\end{tabular}

Note: Complete results including standard errors are found in TABLE B.1 and TABLE B.2. All parameters in this table are highly significant. The parameters are: $\rho$ degree of rigidity, $\sigma_{\varepsilon}$ s.d. of error term of the notional wage change equation; $\sigma_{\mu}$ s.d. of measurement error; $n$ and $c$ are the shares of exactly measured or contaminated observations, respectively; $\sigma_{\mu c}$ s.d. of contamination error. Values of $\ln L$ are not comparable between NME and other models because of the mass points in the MME and CMME models; original values for $\ln L$ have been retained, while the scaling of several parameters has been adjusted to improve readability.

TABLE 2: Composite error model

\begin{tabular}{lllcc} 
& & & Wage earners & Salary earners \\
\hline $\begin{array}{l}\text { Composite error } \\
\text { model }\end{array}$ & $\sigma_{\eta}$ & ${ }^{(1)}$ & 6.4 & 5.8 \\
& $\tilde{\rho}$ & ${ }^{(2)}$ & 0.24 & 0.34 \\
\hline $\mathrm{CMME}^{(*)}$ & $\rho$ & ${ }^{(3)}$ & 0.68 & 0.91 \\
$(2) /(3)[$ in $\%]$ & & ${ }^{(4)}$ & $35.29 \%$ & $37.36 \%$ \\
\hline $\mathrm{HLA}^{(+)}$ & $\rho_{\Delta y}$ & $(5)$ & 0.21 & 0.31 \\
\hline
\end{tabular}

Note: (*) Estimates from the contaminated mixed measurement error (CMME) models in TABLE 1. (+) Estimates from the application of the histogram-location approach (HLA) to the IABS data in Beissinger and Knoppik (2001), p. 25, table 4, row (1), columns (3) and (6). 
TABLE 3: Implications of estimation results

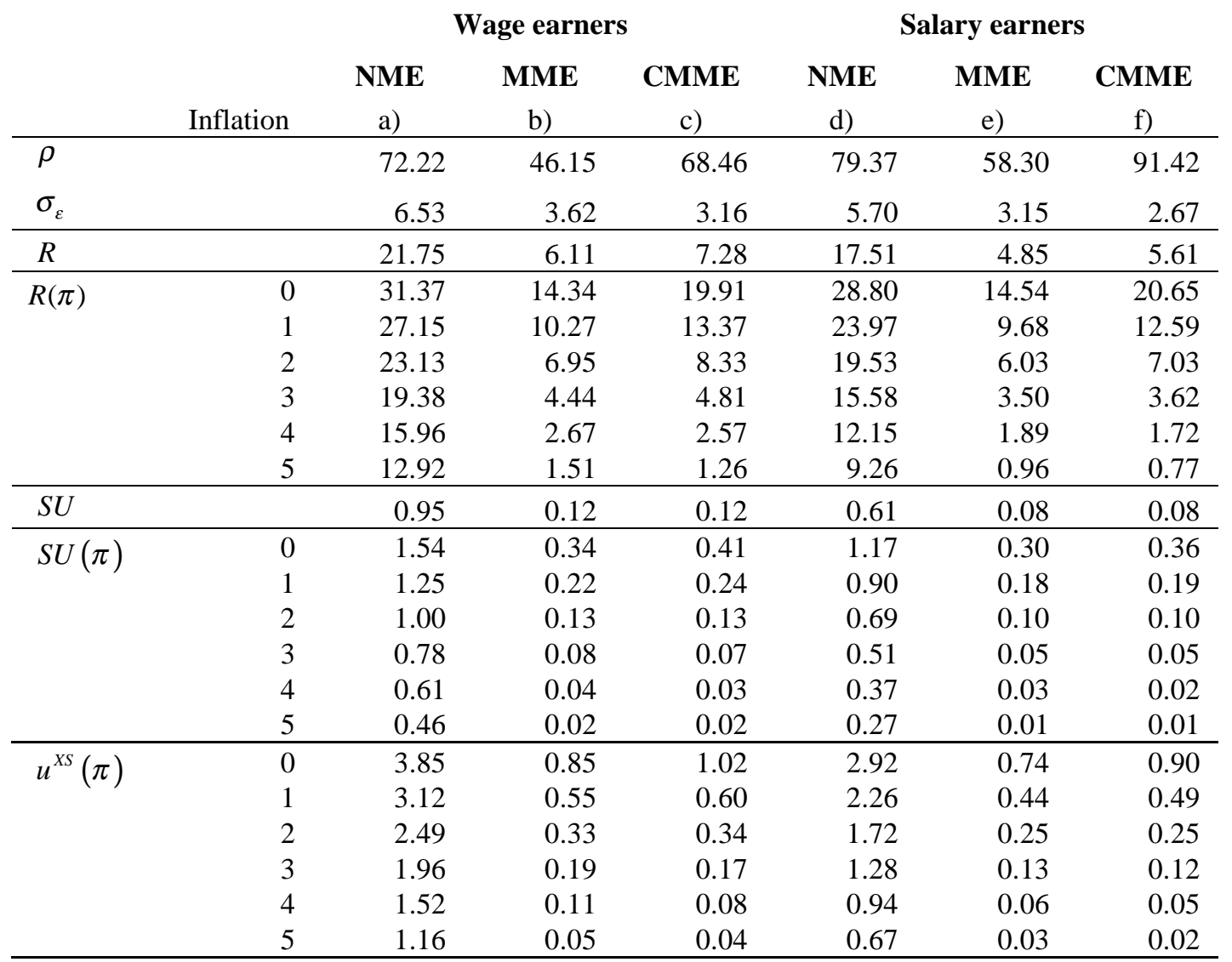

Note: All entries in percent. $R$ and $R(\pi)$ are the shares of affected observations in the sample and under alternative rates of inflation, respectively. $S U$ and $S U(\pi)$ are sweep-up in the sample and under alternative rates of inflation, respectively. $u^{X S}(\pi)$ is excess unemployment for alternative rates of inflation; it is defined as non-accelerating inflation rate of unemployment minus lowest sustainable rate of unemployment $u^{X S}=u^{N A I}-u^{L S}$; for the computation of $u^{X S}$ according to equation (18) $a=0.4$ was used. 
TABLE B.1: Estimation results for workers

NME

MME

CMME

\begin{tabular}{|c|c|c|c|c|c|c|}
\hline DYL & Coef. & Std. Err & Coef. & Std. Err & Coef. & Std. Err \\
\hline EXP & -0.21 & 0.005 & -0.14 & 0.003 & -0.13 & 0.003 \\
\hline EXPS & 0.0026 & 0.0001 & 0.0018 & 0.0001 & 0.0017 & 0.0001 \\
\hline DSt1Sk1 & -1.09 & 0.046 & -0.71 & 0.027 & -0.66 & 0.026 \\
\hline DSt1Sk2 & -1.20 & 0.049 & -0.71 & 0.029 & -0.66 & 0.027 \\
\hline DSt2Sk1 & -0.94 & 0.057 & -0.60 & 0.034 & -0.56 & 0.033 \\
\hline DSt2Sk2 & -1.21 & 0.042 & -0.74 & 0.025 & -0.68 & 0.023 \\
\hline DSt3Sk1 & -0.03 & 0.263 & -0.04 & 0.155 & -0.02 & 0.147 \\
\hline DSt3Sk2 & -0.74 & 0.078 & -0.45 & 0.045 & -0.46 & 0.043 \\
\hline DSt4Sk1 & -0.12 & 0.130 & -0.12 & 0.075 & -0.14 & 0.071 \\
\hline DFOR & -0.03 & 0.033 & -0.08 & 0.022 & -0.07 & 0.021 \\
\hline FAMST & 0.08 & 0.024 & 0.09 & 0.015 & 0.09 & 0.014 \\
\hline Ds1 & -1.74 & 0.128 & -3.17 & 0.079 & -3.50 & 0.081 \\
\hline Ds2 & -0.87 & 0.045 & -1.10 & 0.027 & -1.16 & 0.026 \\
\hline Ds3 & -0.77 & 0.046 & -0.69 & 0.027 & -0.69 & 0.026 \\
\hline Ds4 & -0.49 & 0.039 & -0.43 & 0.024 & -0.42 & 0.023 \\
\hline Ds5 & -0.32 & 0.041 & -0.30 & 0.025 & -0.29 & 0.023 \\
\hline Ds6 & -0.18 & 0.029 & -0.17 & 0.018 & -0.15 & 0.017 \\
\hline CONS & 5.88 & 0.080 & 4.94 & 0.049 & 4.70 & 0.048 \\
\hline D84 & 0.99 & 0.056 & 0.58 & 0.034 & 0.50 & 0.032 \\
\hline INF & 0.48 & 0.012 & 0.35 & 0.007 & 0.34 & 0.007 \\
\hline INF(-1) & 0.25 & 0.017 & 0.26 & 0.011 & 0.25 & 0.010 \\
\hline INF(-2) & 0.27 & 0.000 & 0.39 & 0.000 & 0.41 & 0.000 \\
\hline DU & -1.66 & 0.020 & -1.40 & 0.012 & -1.37 & 0.011 \\
\hline DU(-1) & -1.07 & 0.025 & -0.80 & 0.015 & -0.75 & 0.015 \\
\hline DU(-2) & 0.01 & 0.019 & -0.24 & 0.012 & -0.27 & 0.011 \\
\hline WQNALL & 0.20 & 0.005 & 0.12 & 0.003 & 0.11 & 0.003 \\
\hline$\rho$ & 0.72 & 0.003 & 0.46 & 0.003 & 0.68 & 0.006 \\
\hline$\sigma_{\varepsilon}$ & 6.53 & 0.011 & 3.62 & 0.010 & 3.16 & 0.009 \\
\hline$\sigma_{\mu}$ & 2.95 & 0.013 & 10.10 & 0.032 & 7.50 & 0.031 \\
\hline$n$ & & & 0.74 & 0.002 & 0.60 & 0.002 \\
\hline$\sigma_{\mu c}$ & & & & & 24.12 & 0.352 \\
\hline$c$ & & & & & 0.01 & 0.001 \\
\hline $\ln L$ & 817142.54 & & 722157.55 & & 729258.4 & \\
\hline$N$ & 590570 & & 590570 & & 590570 & \\
\hline
\end{tabular}

Note: The dependent variable is DYL, the log difference of earnings (in percentage points). EXP: experience. EXPS: experience squared. DSTiSkj: dummy variables for skills, reflecting formal skills and occupational status. ST $i$ : different types of occupational status contained in the sample $(i=1, \ldots, 4)$. Sk1 and Sk2: unskilled and skilled employees. DFOR: foreigner dummy. FAMST: marital status. Dsi $(i=1, . ., 6)$ : firm size. D84: dummy for year 1984 due to structural break. INF, INF(-1), INF(-2): current and lagged rates of inflation. DU, DU(-1), DU(-2): current and lagged changes of rates of unemployment. WQNALL: change in the industry employment share (relative to total employment). $\rho, \sigma_{\varepsilon}, \sigma_{\mu}$, $n, c, \sigma_{\mu c}$ : parameters of the NME, MME and CMME models (details see text). $\ln L: \log$ likelihood value; original values for $\ln L$ have been retained, while the scaling of several parameters has been adjusted to improve readability. $N$ : number of observations. 33 dummies for 34 industries were included in the estimation, but are not presented here. 
TABLE B.2: Estimation results for salaried employees

NME Coef. Std. Err

EXP

\section{EXPS}

DSt1Sk1

DSt1Sk2

DSt2Sk1

DSt2Sk2

DSt3Sk1

DSt3Sk2

DSt4Sk1

DFOR

FAMST

Ds1

Ds2

Ds3

Ds4

Ds5

Ds6

CONS

D84

INF

$\operatorname{INF}(-1)$

$\operatorname{INF}(-2)$

DU

DU(-1)

DU(-2

WQNALL

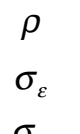

$\sigma_{\mu}$

$n$

$\sigma_{\mu c}$

$c$

$\ln L$

214936.44

144257
MME

CMME

Coef.

Std. Err

0.005

0.0001

0.070

0.058

0.179

0.049

0.182

0.042

0.053

0.084

0.022

0.117

0.044

0.044

0.036

0.037

0.028

0.076

Coef.

Std. Err

$-0.28$

0.0039

$-0.37$

$-0.52$

$-0.48$

$-0.41$

0.10

0.03

$-0.04$

0.10

0.08

$-4.97$

$-1.48$

$-0.59$

$-0.38$

$-0.26$

$-0.08$

6.72

0.005

0.0001

0.065

0.055

0.173

0.046

0.168

0.039

0.050

0.078

0.021

0.132

0.042

0.041

0.034

0.035

0.026

7.16

0.057

1.57

0.073

\subsection{2}

0.012

0.25

0.055

0.24

0.018

0.28

0.011

0.32

0.000

0.47

0.017

0.44

0.020

$-1.09$

0.000

$-1.08$

0.026

$-0.82$

0.018

0.045

$-0.18$

0.019

$-0.21$

0.024

0.018

$0.09 \quad 0.005$

0.08

0.005

$\begin{array}{ll}0.58 & 0.007\end{array}$

0.91

0.012

3.15

0.013

2.67

0.012

11.62

0.083

6.71

0.057

0.83

0.002

0.60

0.002

25.86

0.566

0.02

0.001

209839.21

144257

212789.36

144257

Note: See TABLE B.1. 


\section{Figures in order of appearance in text}

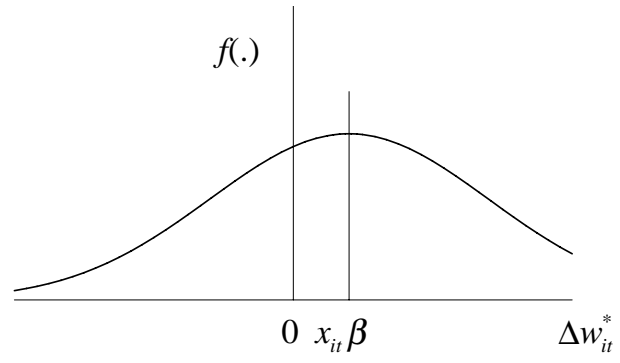

a) Counterfactual density, low $x_{i t} \beta$

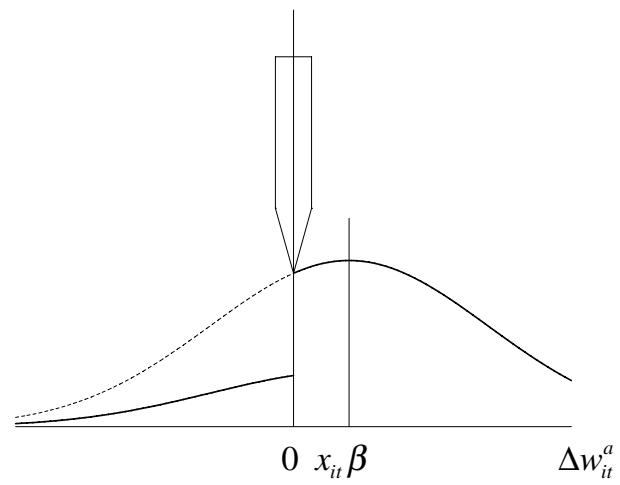

b) Factual pseudo-density, low $x_{i t} \beta$

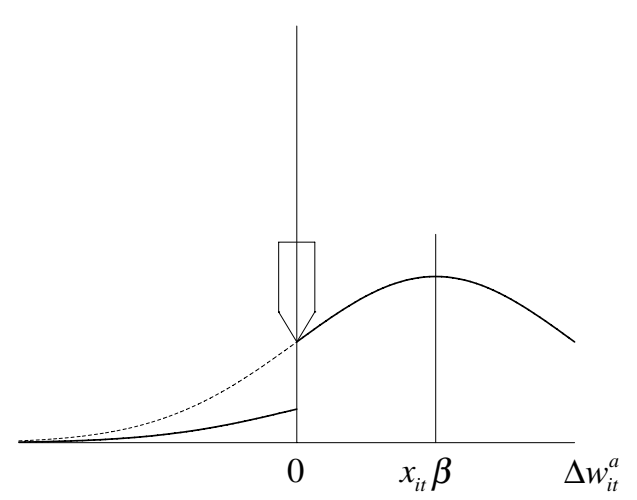

c) Factual pseudo-density, high $x_{i t} \beta$

\section{FIGURE 1: Shape, location and downward nominal wage rigidity}

Note: The shape of the factual distribution in panel b) differs from that of the counterfactual distribution in panel a) because of thinning and pile up. The difference in shape depends on the expected notional wage change $x_{i t} \beta$; it becomes less pronounced for higher $x_{i t} \beta$, as can be seen from panel c). 
촛
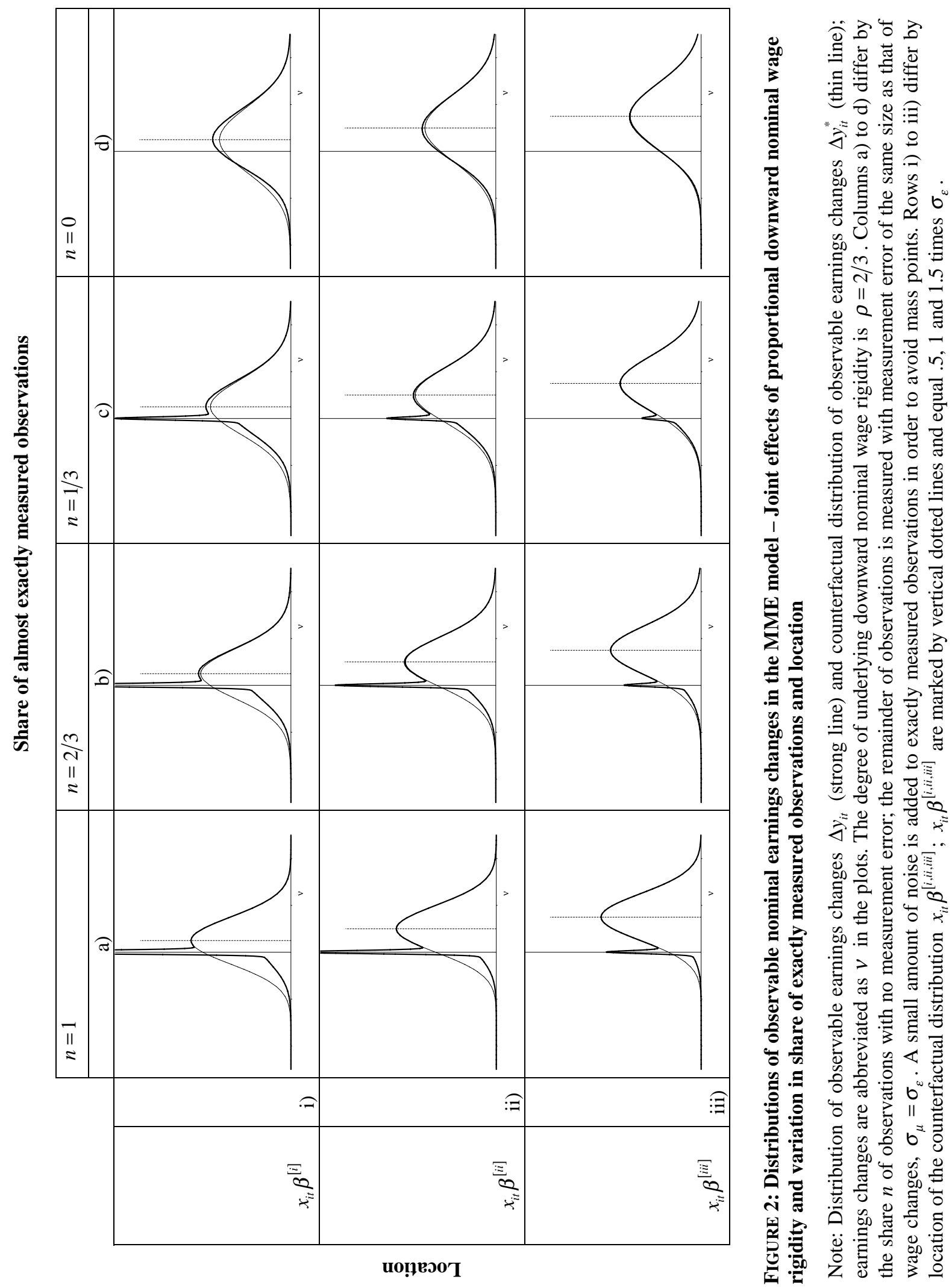


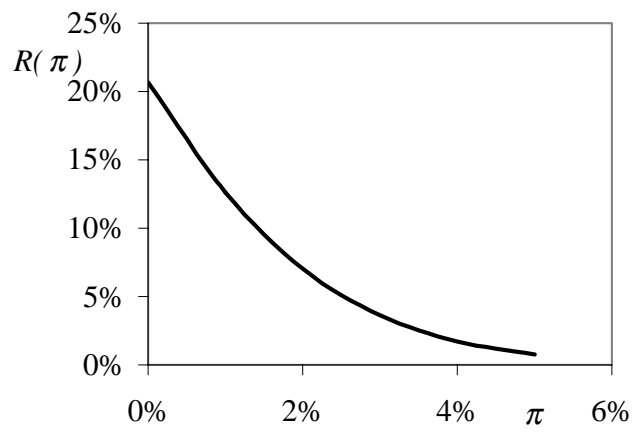

a) Share of affected observations $R(\pi)$

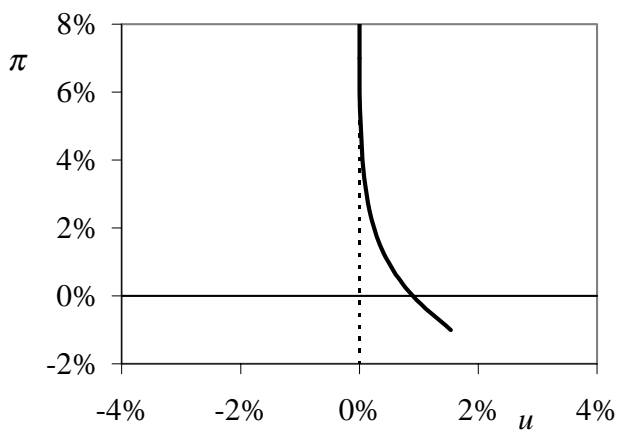

b) Normalized Long-run Phillips Curve

FIGURE 3: Effects of downward nominal wage rigidity at different rates of inflation

Note: Based on CMME estimates for salaried employees. 


\section{IZA Discussion Papers}
No. Author(s)
280
P. Apps
R. Rees
281
G. Saint-Paul
282
J. Albrecht
A. Björklund
S. Vroman
283
M. Hagedorn
A. Kaul
V. Reinthaler

284

H. Rapoport

A. Weiss

285
J. Jerger
C. Pohnke
A. Spermann

286

M. Fertig

C. M. Schmidt

287

P. Guggenberger

A. Kaul

M. Kolmar

288

D. A. Cobb-Clark

289

L. Cameron

D. A. Cobb-Clark

290

D. A. Cobb-Clark

M. D. Connolly

C. Worswick

291
Title

Area

Date

Household Saving and Full Consumption over

7

04/01

the Life Cycle

Information Technology and the Knowledge

5

04/01

Elites

Is There a Glass Ceiling in Sweden?

5

04/01

Welfare Analysis in a Schumpeterian Growth

7

04/01

Model with Capital

The Optimal Size for a Minority

1

$04 / 01$

Gut betreut in den Arbeitsmarkt?

5

Eine mikroökonometrische Evaluation der

Mannheimer Arbeitsvermittlungsagentur

First- and Second-Generation Migrants in

Germany - What Do We Know and What Do

People Think

Efficiency Properties of Labor Taxation in a

3

$04 / 01$

Spatial Model of Restricted Labor Mobility

Getting Ahead: The Determinants of and Payoffs

5

04/01 to Internal Promotion for Young U.S. Men and Women

Old-Age Support in Developing Countries:

3

04/01

Labor Supply, Intergenerational Transfers and Living Arrangements

The Job Search and Education Investments of

1

04/01 Immigrant Families

Cohort Effects in the Educational Attainment of

1

05/01

Second Generation Immigrants in Germany:

An Analysis of Census Data 
N. Smith

L. Husted
G. Brunello
C. Lucifora
R. Winter-Ebmer

300
A. Stutzer
R. Lalive

301

J. R. Frick

G. G. Wagner

302

G. S. Epstein

A. Weiss

303

G. A. Pfann

B. F. Blumberg

304

P. Cahuc

E. Wasmer firm Bargaining 

H. Bonin
G. Abío
E. Berenguer
J. Gil
C. Patxot

307

G. A. Pfann

308

G. A. Pfann

D. S. Hamermesh

309

G. Brunello

310

U. Sunde

311

G. Brunello

312

C. Furnée

M. Kemler

G. A. Pfann

313

A. Ferrer-i-Carbonell

B. M.S. van Praag
Is the Deficit under Control? A Generational Accounting Perspective on Fiscal Policy and Labour Market Trends in Spain 

A. Frederiksen
E. K. Graversen
N. Smith

Works Councils and Collective Bargaining in 

A. Ibourk
B. Maillard

The Matching Efficiency of Regional Labour Models 
